\title{
MODELAGEM DO BALANÇO HÍDRICO EM MICROBACIA CULTIVADA COM PLANTIO COMERCIAL DE Eucalyptus grandis X urophylla NO LESTE DE MINAS GERAIS, BRASIL ${ }^{1}$
}

\author{
André Quintão Almeida ${ }^{2}$, Aristides Ribeiro ${ }^{3}$ e FernandoPalha Leite ${ }^{4}$
}

\begin{abstract}
RESUMO - No Brasil, o número de plantios comerciais de espécies florestais de crescimento rápido vem aumentando consideravelmente nas últimas décadas. Contudo, os possíveis impactos desse aumento sobre os recursos hídricos ainda são desconhecidos. O objetivo deste estudo foi realizar a modelagem do balanço hídrico em uma microbacia cultivada com plantio comercial de híbridos de Eucalyptus grandis x urophylla no Leste de Minas Gerais, Brasil. O trabalho foi realizado em uma microbacia experimental com área total de 40 ha durante o ano hidrológico, compreendido entre outubro de 2009 e setembro de 2010. A principal entrada de água no sistema via precipitação pluvial e os dados meteorológicos foram coletados por uma estação automática instalada no interior da área de estudo. As principais saídas foram estimadas pela equação modificada de Penman-Monteith e pela mensuração do deflúvio gerado na saída da bacia. Do total precipitado $(1.123 \mathrm{~mm})$ durante o ano, $9 \%(106 \mathrm{~mm})$ retornaram à atmosfera via interceptação, $66 \%(740 \mathrm{~mm})$ via transpiração da cultura e $11 \%(119 \mathrm{~mm})$ pela evaporação do solo, que somados corresponderam à aproximadamente $86 \%$ da entrada de água na microbacia. Do deflúvio total gerado $(\sim 147 \mathrm{~mm})$, apenas $4,29 \mathrm{~mm}(0,4 \%)$ foram convertidos em escoamento superficial. Pode-se concluir que durante o ano hidrológico monitorado o balanço entre as principais entradas e as saídas de água na microbacia foi equalizado, não comprometendo a disponibilidade hídrica natural no curso d'água.
\end{abstract}

Palavras-chave: Hidrologia florestal; Modelo de Rutter; Transpiração

\section{THE WATER BALANCE IN WATERSHED WITH COMMERCIAL PLANTATION OF Eucalyptus grandis $X$ urophylla IN EASTERN MINAS GERAIS, BRAZIL}

\begin{abstract}
In Brazil, the number of commercial plantations of forest species has increased considerably in recent decades. However, the potential impacts of this increase on water resources are still unknown. The objective of the present study was to model the water balance in a watershed, home to a commercial plantation of the Eucalyptus grandis $x$ urophylla hybrid in eastern Minas Gerais, Brazil. This study was conducted in an experimental watershed with total area of 40 ha during the hydrological year extending from october 2009 to september 2010. The main source of water entering the system, via rainfall, was monitored as part of meteorological data by an automatic station installed within the study area. The main water outlets were estimated by the modified Penman-Monteith equation and by measuring the runoff generated at the basin output. Of the total precipitation $(1123 \mathrm{~mm})$ during the year, $9 \%(106 \mathrm{~mm})$ was lost via interception, $66 \%$ $(740 \mathrm{~mm})$ via crop transpiration and $11 \%(119 \mathrm{~mm})$ by soil evaporation, which together correspond to approximately $86 \%$ of water entering the watershed. Of the total outflow generated $(\sim 147 \mathrm{~mm})$, only $4.29 \mathrm{~mm}(0.4 \%)$ were converted into surface runoff. It can be concluded that during the hydrological year analyzed, the balance between the main water inputs and outputs in the watershed was equalized, without jeopardizing the availability of water in the natural waterway.
\end{abstract}

Keywords: Forest hydrology; Rutter model; Transpiration.

\footnotetext{
${ }^{1}$ Recebido em 25.10.2012 aceito para publicação em 12.05.2013.

${ }^{2}$ Universidade Federal de Sergipe, Núcleo de Engenharia Agrícola - NEAGRI. E-mail: <andreqa@ gmail.com>.

${ }^{3}$ Universidade Federal de Viçosa, Departamento de Engenharia Agrícola. E-mail: <ribeiro@ufv.br>.

${ }^{4}$ Celulose Nipo Brasileira S A, Coordenação de Pesquisa e Desenvolvimento Florestal - GGF-P.E-mail:<fernando.leite@cenibra.com.br>.
} 


\section{INTRODUÇÃO}

Aproximadamente, mais de 20 milhões de hectares das terras cultivadas com plantios florestais no planeta são de eucalipto, o que corresponde a $10 \%$ da área florestal plantada no mundo (BOOTH, 2012). Aproximadamente, 6,5 milhões de hectares das terras brasileiras estão cobertas com eucalipto, o equivalente a $0,7 \%$ do território nacional (ABRAF, 2011).

Toda mudança de uso da terra promove alterações nos balanços de energia e da água. Podem ser destacadas modificações na radiação solar refletida pela superfície (albedo), na capacidade de infiltração da água no solo, na interceptação da precipitação pluvial, nas taxas de evapotranspiração e na disponibilidade e qualidade da água dos cursos d'água. Nas microbacias cultivadas com floresta de eucalipto, espera-se encontrar um aumento do fluxo de água para o processo de evapotranspiração concomitante com a diminuição do fluxo de água na saída da microbacia, comprometendo, assim, a disponibilidade hídrica natural (VON STACKELBERG et al., 2007; NOTTER et al., 2007; THANAPAKPAWIN et al., 2007; NOSETTO et al., 2011). Estudos apontam que o reflorestamento com eucalipto de áreas degradadas cultivadas com pastagem provoca aumento das perdas de água por evaporação e reduz a produtividade de água (FARLEY et al., 2005; NOSETTO et al., 2005). Na prática, o manejo dos plantios florestais deve encontrar um balanço sustentável entre os fluxos de saída de água, garantindo a disponibilidade natural da água (CALDER, 2007).

Por meio da modelagem dos componentes do balanço de água, pode-se conhecer o rendimento hídrico de uma bacia hidrográfica, indicando seu real potencial produtivo de água. Esse conhecimento é importante para o desenvolvimento de determinada cultura, principalmente culturas florestais. Conhecer os processos de perda de água e os componentes que atuam de forma efetiva no balanço hídrico torna-se, portanto, instrumento de grande importância para a realização de um manejo florestal adequado em microbacias com atividade silvicultural.

Estudos de modelagem dos componentes do balanço hídrico em bacias hidrográficas cultivadas com plantios florestais, principalmente eucalipto, estão sendo realizados em várias partes do mundo (ZHOU et al., 2002; ALMEIDA; SOARES, 2003; LANE et al., 2004;
CABRAL et al., 2010; FEIKEMA et al., 2010; MACFARLANE et al., 2010; FACCO et al., 2012). No Brasil, Almeida et al. (2007) modelaram os componentes do balanço hídrico em uma microbacia hidrográfica cultivada com eucalipto na costa Leste do país, encontrando equilíbrio entre as principais entradas e saídas de água durante os seis primeiros anos de crescimento da espécie.

O objetivo deste trabalho foi realizar a modelagem do balanço hídrico em uma microbacia cultivada com plantio comercial de híbridos de Eucalyptus grandis $\mathrm{x}$ urophylla no Leste de Minas Gerais, Brasil.

\section{MATERIAL E MÉTODOS}

\section{1. Área de trabalho}

O trabalho foi realizado em uma microbacia experimental com área total de 40 ha, localizada (latitude: 19²8'S; longitude: 4249' W; e altitude média: $975 \mathrm{~m}$ ) no Município de Antonio Dias, na porção Leste de Minas Gerais (Figura 1).

A maior parte da microbacia $(78 \%)$ está coberta com plantio comercial de híbridos de Eucalyptus grandis $\mathrm{x}$ urophylla (Figura 1). As árvores do mesmo clone foram plantadas em maio de 2003, com espaçamento estabelecido de 3,0 x 3,3 m, resultando em densidade de 990 árvores por ha. Na microbacia, foram realizadas todas as práticas convencionais de manejo e conservação dos solos e de silvicultura de proteção.

O clima da região, segundo a classificação climática de Köppen, é do tipo frio e úmido (Cwa), com ocorrência de eventos de precipitação ao longo dos meses do ano. A precipitação média anual é de $1.281 \mathrm{~mm}$ e a temperatura média do ar anual, $20,3{ }^{\circ} \mathrm{C}$.

O solo característico da microbacia é do tipo Cambissolo Háplico Distrófico Latossólico, com textura argilosa cascalhenta. As principais características físicas e texturais do solo podem ser visualizadas na Tabela 1. O relevo da microbacia é fortemente ondulado, com altitude variando entre 900 e 1.000 m e declividade média de $42 \%$.

\subsection{Período de estudo e coleta de dados}

A modelagem do balanço hídrico foi realizada durante o ano hidrológico compreendido entre outubro de 2009 e setembro de 2010, início e fim, respectivamente, do período chuvoso e seco na região. 
As variáveis meteorológicas medidas e necessárias para a realização do estudo foram: temperatura $\left({ }^{\circ} \mathrm{C}\right)$ e umidade relativa do ar (\%); radiação solar global (MJ $\left.\mathrm{m}^{-2} \mathrm{~s}^{-1}\right)$; velocidade do vento $\left(\mathrm{m} \mathrm{s}^{-1}\right)$; fluxo de calor no solo $\left(\mathrm{MJ} \mathrm{m}^{-2} \mathrm{~s}^{-1}\right)$; e precipitação pluvial $(\mathrm{mm})$. Os dados foram obtidos por sensores instalados na parte superior de uma estação meteorológica automática (torre com $30 \mathrm{~m}$ de altura) inserida no interior da microbacia

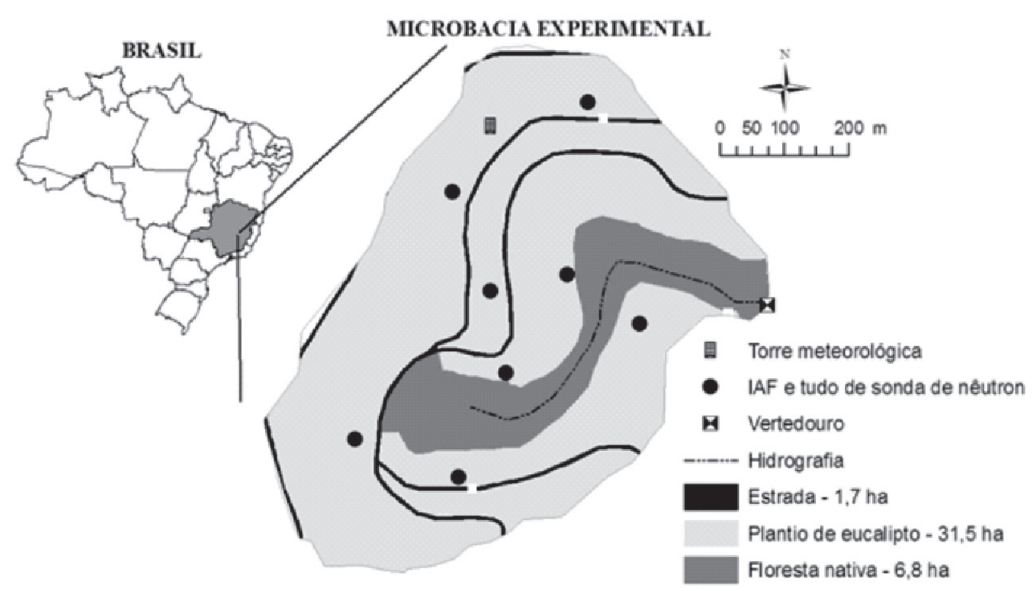

Figura 1 - Localização e instrumentação da microbacia experimental cultivada com plantio comercial de híbridos de E. grandis $\mathrm{x}$ urophylla, no Leste de Minas Gerais, Brasil.

Figure 1 - Location of instrumentation in the experimental watershed, home to a commercial plantation of the E. grandis $x$ urophylla hybrid in eastern MG, Brazil.

Tabela 1 - Parâmetros utilizados no estudo de modelagem do balanço hídrico da microbacia experimental com plantios comerciais de híbridos de $\boldsymbol{E}$. grandis x urophylla.

Table 1 - Parameters used in the study for modeling of the water balance in the experimental watershed, home to commercial plantations of the E. grandis $x$ urophylla hybrid.

\begin{tabular}{|c|c|c|}
\hline Parâmetro & Valor & Fonte \\
\hline Beer-Lambert $(k)$ & $-0,42$ & \\
\hline *Índice de área foliar médio - IAF $\left(\mathrm{m}^{2} \mathrm{~m}^{-2}\right)$ & 2,5 & \\
\hline Resistência aerodinâmica $-r_{a}\left(m s^{-1}\right)$ & 83 & Hatton et al. (1992) \\
\hline Resistência máxima do solo $-r_{\text {solo }}\left(m^{-1}\right)$ & 0,0025 & Choudhury e Monteith (1988) \\
\hline Resistência aerodinâmica do solo $-r_{\text {asolo }}\left(\mathrm{m} \mathrm{s}^{-1}\right)$ & 0,012 & Choudhury e Monteith (1988) \\
\hline Coeficiente de precipitação interna ditreta - $p(a d m)$ & 0,42 & Steidle Neto et al. (2012) \\
\hline Coeficiente de escoamento do tronco e galhos - pt (adm) & 0,03 & Steidle Neto et al. (2012) \\
\hline Capacidade de retenção da copa $-S(\mathrm{~mm})$ & 0,24 & Steidle Neto et al. (2012) \\
\hline Capacidade de retenção do tronco - $S t(\mathrm{~mm})$ & 0,04 & Steidle Neto et al. (2012) \\
\hline Profundidade do sistema radicular $(\mathrm{m})$ & 2,50 & \\
\hline Tipo de solo & CXbd & \\
\hline Areia (\%) & 47 & \\
\hline Silte $(\%)$ & 14 & \\
\hline Argila (\%) & 39 & \\
\hline Densidade do solo $\left(\mathrm{g} \mathrm{cm}^{-3}\right)$ & 0,94 & \\
\hline Porosidade (\%) & 62 & \\
\hline Capacidade de campo $(\mathrm{mm})$ & 567 & \\
\hline Ponto de murcha $(\mathrm{mm})$ & 371 & \\
\hline Capacidade de água disponível no solo (mm) & 196 & \\
\hline Água inicial disponível no solo (mm) & 70 & \\
\hline
\end{tabular}

*Índice de área Foliar (Método não destrutivo - LAI2000); As características físicas dos solos correspondem ao perfil de 0 a 2,5 metros de profundidade; Densidade do solo (Método do anel volumétrico); Porosidade (Método dos anéis concêntricos). 
e armazenados em um DataLogger, modelo CR1000 (Figura 1). Toda coleta de dados foi realizada na escala de tempo horária. Os valores de fluxo de calor no solo foram estimados pela média das leituras de dois sensores instalados a 0,05 $\mathrm{m}$ de profundidade no solo, um na linha e outro na entrelinha do plantio.

Na saída da microbacia foi instalada uma barragem com vertedouro triangular com abertura de $45^{\circ}$. A vazão do curso d'água $\left(\mathrm{L} \mathrm{s}^{-1}\right)$ foi medida com o auxílio de um linígrafo do tipo Thalimedes, da marca OTT. A carga hidráulica (altura da lâmina d'água) foi armazenada a cada $5 \mathrm{~min}$, e, posteriormente, os valores foram convertidos em vazão (Q), a partir da equação 1 .

$$
Q=\frac{8}{15} C d \sqrt{2 g}\left(\tan \frac{45}{2}\right) \text { alt }^{5 / 2}
$$

em que Q é a vazão em L s ${ }^{-1}$; alt, a carga hidráulica (m); $\mathrm{C}_{\mathrm{d}}$, o coeficiente de descarga $(0,797377) ; \mathrm{g}$, a gravidade $\left(\mathrm{m} \mathrm{s}^{-2}\right)$; e 45, o ângulo de abertura do vertedouro.

O deflúvio total gerado ( Def $_{\text {total }}$ ), em milímetros, a cada hora foi calculado pela integração dos valores de Q $\left(\mathrm{L} \mathrm{s}^{-1}\right)$ instantâneos de 5 min $(300 \mathrm{~s})$ e pela sua relação com a área $\left(\mathrm{m}^{2}\right)$ da microbacia.

O Índice de Área Foliar (IAF) do plantio de eucalipto foi estimado de forma não destrutiva com o analisador de dossel LAI-2000 (Licor, Lincoln, Nebraska, USA). As estimativas foram realizadas em diferentes datas (1/12/2009, 15/01/2010, 12/04/2010 e 5/08/2010) e pontos da microbacia (Figura 1), ao amanhecer ou pôr do sol. Para as respectivas datas, o IAF de cada ponto corresponde à média de 10 leituras consecutivas abaixo do dossel e o do plantio, à média dos oito pontos.

\subsection{Modelagem do balanço hídrico}

O modelo do balanço hídrico utilizado parte de algumas premissas, considerando-se fluxos de entrada e saída. Pressupõe-se, também, que não existam falhas geológicas na microbacia capazes de realizar trocas subterrâneas de água com outras áreas. Na Tabela 1, apresentam-se os principais parâmetros utilizados na modelagem dos componentes do balanço hídrico da microbacia.

A modelagem foi realizada no espaço de tempo diário, considerando-se a precipitação pluvial a única entrada de água e o processo de evapotranspiração e o deflúvio gerado no vertedouro, as principais saídas da microbacia (equação 2).

$$
A D S_{\text {dia } i}=A D S_{\text {dia } i-1}+\left(P_{\text {diai }}-I_{\text {diai }}\right)-T_{\text {diai }}-E_{\text {solodiai }}-D e f_{\text {diai }}
$$

em que $\operatorname{ADS}_{\mathrm{i}}$ é a água disponível no solo no dia $i$; $\mathrm{ASD}_{\mathrm{i}-1}$, a água disponível no solo no dia anterior $i$ 1; P, a precipitação acima do dossel vegetal no dia $i$; I, a interceptação da precipitação pluvial do eucalipto no dia $i$; $\mathrm{T}$, a transpiração do eucalipto no dia $i$; $\mathrm{E}_{\text {solo, }}$, a evaporação do solo no dia $i$; e Def, o deflúvio total gerado na saída da microbacia no dia $i$ todos os componentes foram dados em milímetros.

A interceptação da precipitação pluvial (I) foi estimada pelo modelo de Rutter (RUTTER et al., 1975). Os principais parâmetros de entrada do modelo de Rutter estão apresentados na Tabela 1. Os valores foram selecionados com base no trabalho de Steidle Neto et al. (2012) em plantios comercias de Eucalyptus grandis $\mathrm{x}$ urophylla localizados próximos da microbacia experimental.

A estimativa da transpiração $(\mathrm{T})$ foi realizada a partir da equação modificada de Penman-Monteith na resistência estomática, de acordo com a metodologia proposta por Carneiro et al. (2008).

$$
\lambda T=\frac{s(R n-G)+M \rho_{a} c_{p} D P V / r_{a}}{s+\gamma\left(1+r_{s} / r_{a}\right)}
$$

em que T é a transpiração $\left(\mathrm{mm} \mathrm{h}^{-1}\right)$; $\mathrm{s}$ a declividade da curva de pressão de saturação do ar à temperatura do ar $\mathrm{t}\left(\mathrm{kPa}^{\circ} \mathrm{C}^{-1}\right) ; \mathrm{R}_{\mathrm{n}}$, o balanço de radiação acima do dossel (MJ m ${ }^{-2} \mathrm{~h}^{-1}$ ); G, o fluxo de calor no solo (MJ $\left.\mathrm{m}^{-2} \mathrm{~h}^{-1}\right) ; \mathrm{M}$, o fator de ajuste de escala (3.600 para uma hora); $\tilde{\mathrm{n}}_{\mathrm{a}}$, a densidade média do $\operatorname{ar}\left(\mathrm{kg} \mathrm{m}^{-3}\right) ; \mathrm{c}_{\mathrm{p}}$, o calor específico do ar $\left(\mathrm{MJ} \mathrm{kg}^{-1}{ }^{\circ} \mathrm{C}^{-1}\right)$; ë, o calor latente de evaporação ( $\mathrm{MJ} \mathrm{kg}^{-1}$ ); DPV, kPa; ã, a constante psicrométrica $\left(\mathrm{kPa}^{\circ} \mathrm{C}^{-1}\right) ; \mathrm{r}_{\mathrm{a}}$, a resistência aerodinâmica $\left(\mathrm{s} \mathrm{m}^{-1}\right)$; e $\mathrm{r}_{\mathrm{s}}$, a resistência imposta pelo dossel $\left(\mathrm{s} \mathrm{m}^{-1}\right)$.

O valor adotado de resistência aerodinâmica $\left(r_{a}\right)$ foi de $83 \mathrm{~s} \mathrm{~m}^{-1}$, com base no estudo de Hatton et al. (1992) com árvores de eucalipto da espécie Maculata e no trabalho de Soares e Almeida (2001) em Eucalyptus grandis. A resistência do dossel foi estimada, dividindo-se a resistência estomática $\left(\mathrm{r}_{\mathrm{s}}\right)$ modelada pelo valor de IAF do plantio. A resistência estomática foi estimada a partir do modelo desenvolvido por Carneiro et al. (2008) em plantios comerciais de eucalipto da mesma espécie na região Leste de Minas Gerais. Nesse modelo,

Revista Árvore, Viçosa-MG, v.37, n.3, p.547-556, 2013 
a $\mathrm{r}_{\mathrm{s}}$ é modelada em função da temperatura, do déficit de pressão de vapor do ar e da irradiância solar global, a cada hora (equação 4).

$$
r_{s}=418,74\left(D P V t_{\text {med }} R_{g}^{-1}\right)^{0,5415}
$$

em que $\mathrm{r}_{\mathrm{s}}$ está em $\mathrm{m} \mathrm{s}^{-1} ; \mathrm{t}_{\text {med }}$ é a temperatura média do $\operatorname{ar}\left(\mathrm{em}^{\circ} \mathrm{C}\right)$; DPV, o déficit de pressão de vapor do $\operatorname{ar}(\mathrm{kPa})$; e $\mathrm{R}_{\mathrm{g}}$, a irradiância solar global incidente $\left(\mathrm{W} \mathrm{m}^{-2} \mathrm{~s}^{-1}\right)$, todos em hora.

A evaporação do solo $\left(\mathrm{E}_{\text {solo }}\right)$ foi estimada pela equação de Penman-Monteith, com a resistência do solo $\left(\mathrm{r}_{\text {solo }}\right)$ diminuindo rapidamente à medida que a disponibilidade de água no solo (ADS) decresce, conforme Choudhury e Monteith (1988) e Soares e Almeida (2001). A resistência aerodinâmica do solo $\left(\mathrm{r}_{\text {asolo }}\right)$ adotada foi de 0,012 $\mathrm{m} \mathrm{s}^{-1}$, segundo Choudhury e Monteith (1988). O fluxo de radiação líquida que chega até a superfície do solo $\left(\mathrm{R}_{\text {nsolo }}\right)$ foi estimado com base na formulação da Lei de Beer (equação 5).

$$
R_{\text {nsolo }}=R_{n} \exp (k I A F)
$$

em que k é o coeficiente de extinção $(-0,42)$ usado por Hatton et al. (1992).

A resistência do solo $\left(\mathrm{r}_{\text {solo }}\right)$ foi estimada, conforme Choudhury e Monteith (1988) e Soares e Almeida (2001), conforme a equação 6 .

$$
r_{\text {solo }}=0,0025 \frac{A D S}{C A D}
$$

em que $\mathrm{r}_{\text {solo }}$ é a resistência do solo $\left(\mathrm{m} \mathrm{s}^{-1}\right)$; ADS, a água disponível no solo (mm); e CAD, a capacidade de água disponível no solo ( $\mathrm{mm}$ ).

\subsection{Conteúdo de água no solo}

A água disponível no solo foi medida em campo pelo método de atenuação de nêutrons. As leituras de contagem de nêutron foram realizadas por uma sonda (Modelo 503 DR-HIDROPROBE, CPN International Inc., Martinez California EUA) em oito tubos de acesso com 2,5 $\mathrm{m}$ de comprimento e $45 \mathrm{~mm}$ de diâmetro interno (Figura 1). As medições foram realizadas em sete diferentes datas do ano hidrológico, em intervalos (camadas) de $0,2 \mathrm{~m}$ de solo até a profundidade de 2,5 m. O volume de água $(\mathrm{mm})$ em cada camada foi estimado pelo produto entre o conteúdo volumétrico $\left(\mathrm{cm}^{3} \mathrm{~cm}^{-3}\right)$ e a espessura dessa camada $(0,2 \mathrm{~mm})$. O conteúdo total de água no solo ( $\mathrm{mm}$ ) até a zona das raízes foi dado pela soma do conteúdo de água de cada camada. Os valores medidos de água disponível no solo foram comparados com os valores estimados pelo modelo de balanço hídrico.

Equações de calibração entre os valores de contagem de nêutron da sonda e umidade volumétrica $\left(\mathrm{cm}^{3} \mathrm{~cm}^{-}\right.$ ${ }^{3}$ ) foram ajustadas para o solo da microbacia.

\subsection{Individualização do escoamento superficial}

A lâmina de escoamento superficial ( $\mathrm{Esc}_{\text {sup }}$ ) foi estimada pela análise gráfica dos valores totais escoados $\left(\right.$ Def $_{\text {total }}$ ) e precipitados (P) em cada hora. O escoamento superficial se iniciou na hora $i$, que foi observada a ocorrência de um evento de precipitação e o aumento no valor do escoamento total. Foi considerado que o final do escoamento superficial ocorreu $1 \mathrm{~h}$ após o término da precipitação, sendo esse o tempo de concentração $\left(T_{c}\right)$ decorrido para que toda a área de drenagem da respectiva microbacia levasse para contribuir com o Esc sup $_{\text {. }} \mathrm{O}_{\mathrm{c}}$ médio estimado pela equação de Kirpich (1940) para a microbacia foi de $5 \mathrm{~min}$, portanto, na hora após o término da precipitação, toda a precipitação já havia contribuído com o Esc sup $_{\text {. }}$.

\section{RESULTADOS}

Na Figura 2 pode ser observada a variação sazonal do processo de evapotranspiração e do saldo de radiação ao longo do ano hidrológico analisado. O valor médio evapotranspirado no período foi de aproximadamente $2,5 \mathrm{~mm}$.

Na Figura 3 são apresentadas, de forma individualizada, as principais lâminas de escoamento observadas no vertedouro instalado na saída da microbacia. Pode-se notar a geração de deflúvio durante todos os dias do ano hidrológico considerado, com um valor total no ano de $147 \mathrm{~mm}$. Desse total acumulado, apenas $4,3 \mathrm{~mm}$ foram convertidos em escoamento superficial.

A Figura 4 mostra as variações diárias de água disponível no solo até a profundidade do sistema radicular, estimada (linha) e medida (ponto), e os valores de precipitação pluvial durante o ano hidrológico considerado. Os maiores valores de água disponível no solo foram observados no período chuvoso do ano hidrológico, entre novembro e março, estando o solo próximo da capacidade máxima de água disponível (196 mm). Durante o inverno, junho a setembro, ocorreram

Revista Árvore, Viçosa-MG, v.37, n.3, p.547-556, 2013 
os menores valores de conteúdo de água no solo, estando boa parte desse período próxima do ponto de murcha permanente.

\section{DISCUSSÃO}

Neste estudo, a precipitação pluvial foi a única entrada de água no sistema, sendo desconsiderados os processos de drenagem lateral e irrigação. O total precipitado no interior da microbacia durante o ano hidrológico de outubro de 2009 a setembro de 2010 foi abaixo da média histórica $(1.281 \mathrm{~mm})$ da região, com base em uma série de dados pluviométricos maior que 30 anos. Apesar do baixo valor precipitado no ano hidrológico considerado, normalmente o clima na microbacia é frio e úmido, com chuva bem

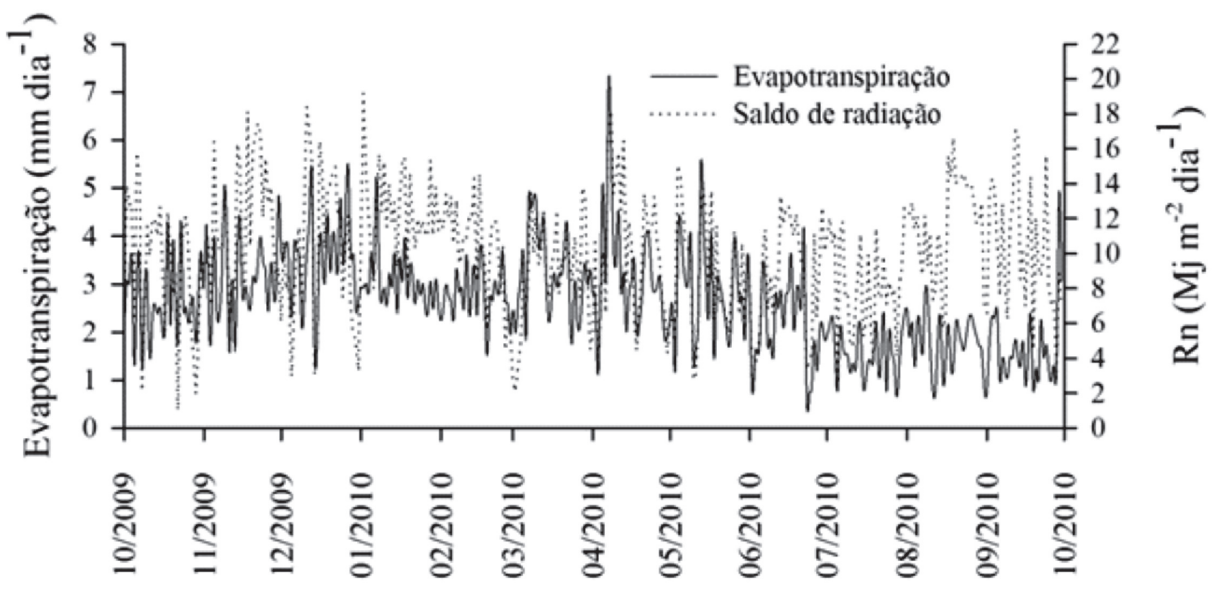

Figura 2 - Valores totais diários de evapotranspiração (linha sólida) e saldo de radiação (linha tracejada) na microbacia experimental com plantio comercial de E. grandis x urophylla, no ano hidrológico outubro de 2009 - setembro de 2010.

Figure 2 - Total daily values of evapotranspiration (solid line) and net radiation (dashed line) in the experimental watershed with commercial plantation of the $\boldsymbol{E}$. grandis $x$ urophylla hybrid during the hydrological year of october 2009 - september 2010.

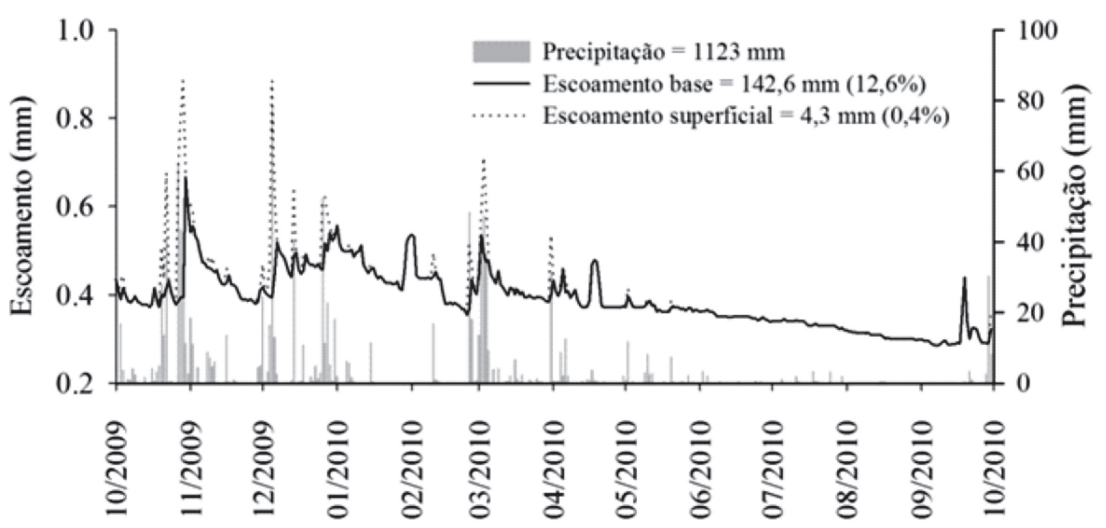

Figura 3 - Valores totais diários de escoamento (deflúvio) gerado na saída da microbacia experimental com plantio comercial de E. grandis x urophylla e precipitação pluvial (barras), no ano hidrológico outubro de 2009 - setembro 2010.

Figure 3 - Total daily values of flow generated at the output of the experimental watershed with commercial plantation of the E. grandis $x$ urophylla hybrid and rainfall (bars) for the hydrological year of october 2009 -september 2010.

Revista Árvore, Viçosa-MG, v.37, n.3, p.547-556, 2013 


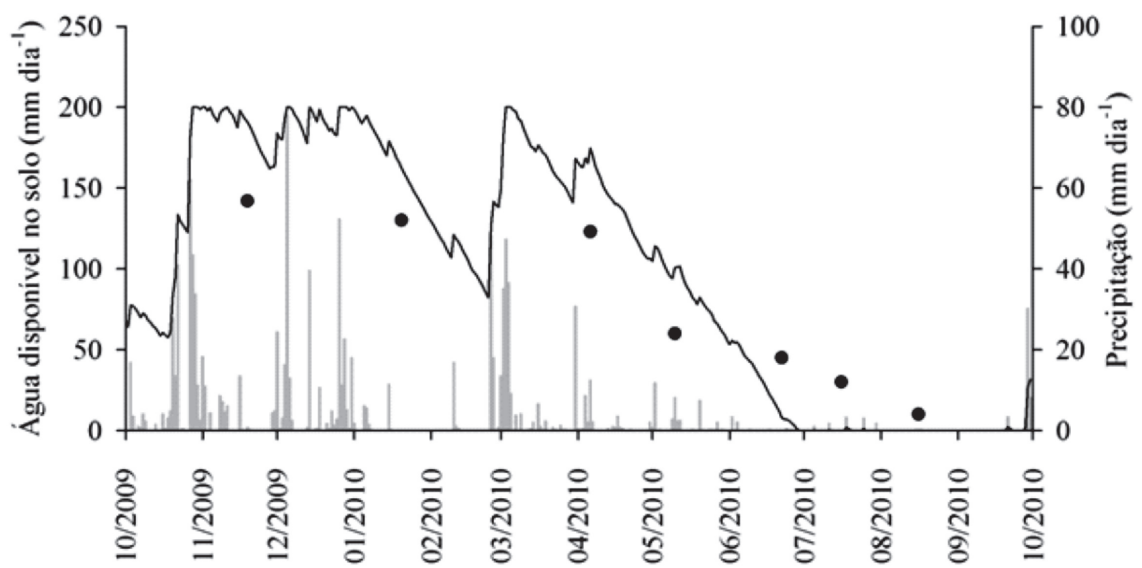

Figura 4 - Valores diários de água disponível no solo modelada (linha) e medida (círculo) até a profundidade do sistema radicular $(2,5 \mathrm{~m})$, com valores de precipitação pluvial (barras) do ano hidrológico outubro 2009 - setembro 2010.

Figure 4-Modeled (line) and measured (circle) values of water available in the soil to the depth of the root system (2.5 $m$ ), with rainfall values (bars) for the hydrological year of october 2009 - september 2010.

distribuída ao longo do ano e baixa demanda evapotranspirativa.

A evapotranspiração (ET), dada pela soma da interceptação, da transpiração e da evaporação do solo, foi o principal processo de saída de água do sistema (965 mm), com valor médio diário de 2,5 mm (Figura 2). A relação entre o total evapotranspirado na microbacia e o total precipitado foi de 0,86 , significando que $86 \%$ do total precipitado voltou para a atmosfera via evapotranspiração. Esse resultado indica que, mesmo com o total precipitado abaixo do normal climatológico, o sistema não precisou utilizar reservas hídricas do solo, garantindo o deflúvio na saída da microbacia durante todo o período analisado (Figura 3). Na avaliação do consumo de água de plantios comerciais de eucalipto na costa Leste do Brasil, Almeida e Soares (2003) encontraram resultados da relação ET/P próximos da unidade, mesmo quando o ano hidrológico apresentou valor total precipitado superior ao do histórico climatológico da região.

Considerando apenas a transpiração (T), esta foi responsável pelo consumo de $66 \%$ do total precipitado, com um valor médio diário de 1,9 $\mathrm{mm}$. Esses resultados são semelhantes ao encontrado por Forrester et al. (2010) em plantios comerciais de eucalipto aos 7 anos de idade na Austrália, mesma idade do plantio analisado neste trabalho. Outros estudos (SOARES; ALMEIDA, 2003; CABRAL et al., 2010) indicaram que a transpiração em plantios comerciais de eucalipto segue a mesma variação do saldo de radiação, estando, portanto, na maior parte do tempo, em razão dessa variável ambiental. O mesmo comportamento também foi observado na microbacia experimental (Figura 3). Alguns trabalhos apontaram que $80 \%$ dos valores de transpiração podem ser governados pelo saldo de radiação (CABRAL et al., 2010). É importante ressaltar também que a transpiração varia com o estágio de desenvolvimento (idade) da cultura, com as estações do ano e com as características climáticas do local (FEIKEMA et al., 2010).

O valor total evaporado do solo $\left(\mathrm{E}_{\text {solo }}\right)$ foi de 119 $\mathrm{mm}$. Apesar de ser desconsiderada na maioria dos estudos de modelagem do balanço hídrico de microbacias hidrográficas com aptidão silvicultural, a evaporação do solo mostrou ter participação importante no processo total de evapotranspiração, com $11 \%$ de contribuição em relação ao valor total precipitado. Esse valor foi semelhante ao encontrado por Soares e Almeida (2001), em uma microbacia experimental com plantios de Eucalyptus grandis aos 9 anos de idade, localizada no Estado do Espírito Santo.

O processo de interceptação da precipitação pluvial (I) foi responsável pelo consumo de $9 \%$ do total precipitado durante o ano hidrológico. Apesar de ter sido estimada via modelo de Rutter, a porcentagem interceptada pelo dossel florestal na microbacia foi

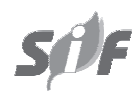

Revista Árvore, Viçosa-MG, v.37, n.3, p.547-556, 2013 
semelhante ao encontrado por Lane et al. (2004) no Sudeste da China e por Steidle Neto et al. (2012) no Leste do Brasil, em plantios comerciais de espécies do gênero Eucalyptus. O total interceptado pela cobertura vegetal está altamente relacionado com a intensidade e duração da precipitação, arquitetura da copa, IAF, características morfológicas do fuste e o número de árvores por hectare, podendo contribuir com até $25 \%$ da precipitação total incidente (LLORENS; DOMINGO, 2007).

Aproximadamente, $13 \%$ da entrada de água no sistema foi convertido em vazão (deflúvio) no curso d'água (Figura 3), suprimindo as demais demandas hídricas no interior e fora do contexto da microbacia. Em relação ao deflúvio gerado (147 mm), apenas 0,4\% foi convertido em escoamento superficial ( Esc $_{\text {sup }}$ ). Resultados semelhantes foram encontrados por Silva et al. (2011) em plantios comerciais de eucalipto localizados na bacia do rio Doce, em Minas Gerais. Apesar do relevo montanhoso (declividade média de $42 \%$ ), o valor total do $\mathrm{Esc}_{\text {sup }}$ verificado durante o ano hidrológico na microbacia é considerado baixo, principalmente quando comparado com resultados encontrados em outras microbacias cultivadas com eucalipto (SOARES; ALMEIDA, 2003; ALMEIDA et al., 2007). Os baixos valores de escoamento superficial estão associados com a cobertura florestal, a qual intercepta maior porcentagem da precipitação pluvial e promove melhorias nas características físicas do solo, como a porosidade e as taxas de infiltração de água. Os benefícios da cobertura florestal na regularização da vazão do curso d'água podem ser observados pela análise detalhada da Figura 3. Nota-se, nessa figura, que, mesmo nos dias com elevados valores de precipitação pluvial, a variação na vazão foi próxima do valor médio observado no ano. Boa parte do escoamento superficial está relacionada com a precipitação pluvial incidente diretamente no canal da microbacia (SOARES; ALMEIDA, 2003). Em campo, foi observado também que a água drenada pelas estradas vicinais teve contribuição significativa no total escoado superficialmente $\left(\operatorname{Esc}_{\text {sup }}\right)$.

O modelo do balanço hídrico conseguiu explicar 99\% da entrada de água no sistema via precipitação pluvial. A análise dos principais componentes do balanço hídrico na microbacia comprova o equilíbrio entre o total evapotranspirado pelo cultivo florestal e o total precipitado. Apenas no final do ano hidrológico (Figura 2), período com baixa ocorrência de precipitação pluvial, a ADS chegou próxima ao valor do ponto de murcha permanente $(371 \mathrm{~mm})$.

O bom desempenho do modelo do balanço de água indica que os valores estimados de evapotranspiração não foram superestimados. Mesmo com poucos pontos medidos de água disponível no solo, ao analisar a Figura 4 notou-se clara correspondência entre os valores medidos e modelados, indicando que o modelo conseguiu descrever satisfatoriamente os principais componentes do balanço hídrico da microbacia. Entretanto, percebeu-se que o modelo superestimou os valores de água disponível no solo nos períodos mais úmidos do ano e os subestimou no período mais seco. Vale ressaltar que foram considerados os valores de umidade de água no solo de apenas um tubo de acesso, dos oito que foram monitorados no interior da microbacia.

No Brasil, assim como em outras regiões tropicais, existe grande discussão com relação ao consumo de água por parte dos plantios comerciais de florestas de crescimento rápido, principalmente as do gênero eucalipto. Os resultados deste estudo indicaram que, em regiões com precipitação anual climatológica próxima de $1.200 \mathrm{~mm}$ e baixa demanda evapotranspirativa, a disponibilidade hídrica natural nas microbacias hidrográficas foi assegurada.

\section{CONCLUSÃO}

O processo de evapotranspiração foi o principal componente de perda de água na microbacia.

O modelo de balanço hídrico utilizado estimou, com confiabilidade, a água disponível no solo da microbacia experimental.

A análise detalhada dos componentes do balanço hídrico indica que a disponibilidade hídrica natural da microbacia não foi comprometida durante o ano hidrológico, garantindo deflúvio durante todo o período analisado.

\section{AGRADECIMENTOS}

À empresa florestal CENIBRA, por ter concedido e financiado a execução do projeto, bem como por todo o suporte logístico e técnico para sua execução; e à Coordenação de Aperfeiçoamento de Pessoal de Nível Superior (CAPES), pelo apoio financeiro. 


\section{REFERÊNCIAS}

ASSOCIAÇÃO BRASILEIRA FLORESTALABRAF. Anuário Estatístico da ABRAF 2008 - Ano Base 2011. http://www.abraflor.org.br/ . Acesso em: 22 de abr. de 2013.

ALMEIDA, A. C.; SOARES, J.V.Comparação entre uso de água em plantações de Eucalyptusgrandise Floresta Ombrófila densa (Mata Atlântica) na costa leste do Brasil. Revista Árvore,v.27, n.2, p.159-170, 2003.

ALMEIDA, A. C. et al. Growth and water balance of Eucalyptus grandis hybrid plantations in Brazil during a rotation for pulp production. Forest Ecology and Management, v.251, n.1, p.10-21, 2007.

BOOTH, T. H. EucalyptsandTheirPotential for InvasivenessParticularly in Frost-Prone Regions. International Journal of Forestry Research, v.2012, p.1-7, 2012. doi:10.1155/2012/837165.

CABRAL, O. M. R. et al. The energy and water balance of a Eucalyptus plantation in southeast Brazil. Journal of Hydrology, v.388, n.3 p.208-216, 2010.

CALDER, I. R. Forests and water: ensuring forest benefits outweigh water costs.Forest Ecology and Management, v.251, n.251, p. 110-120, 2007.

CARNEIRO, R. L. et al. Consumo de água em plantios de eucalipto: parte 2 modelagem da resistência estomática e estimativa da transpiração em tratamentos irrigados e não-irrigados.

Revista Árvore, v.32, n.1, p.11-18, 2008.

CHOUDHURY, B. J.; MONTEITH, J. L. A fourlayermodel for the heat budget of homogeneous land surfaces.Quarterly Journal of the Royal Meteorological Society,v.114, n.480, p.373-398, 1988.

FACCO, A. G. et al.Técnicas de geoinformação para estimativa do balanço hídrico em eucalipto. Pesquisa Agropecuária Brasileira, v. 47, n.9, p. 1243-1250, 2012.

FARLEY, K. A. et al. Effects of afforestation on water yield: a global synthesis with implications for policy. Global Change Biology, v.11, n.10, p.1565-1576, 2005.
FEIKEMA, P. M. et al. Validation of plantation transpiration in south-eastern Australia estimated using the $3 \mathrm{PG}+$ forest growth model. Forest Ecology and Management, v.260, n.5, p.663-678, 2010.

FORRESTER, D. I. et al. Enhanced water use efficiency in a mixed Eucalyptus globulus and Acacia mearnsii plantation. Forest Ecology and Management, v.259, n.9, p.1761-1770, 2010.

HATTON, T. J.et al. Simulation of hydroecological responses to elevated $\mathrm{CO} 2$ at the catchment scale. Australian Journal Botany, v.40, n.4, p.679-696, 1992.

KIRPICH, Z. P. Time of concentration of small agricultural watersheds. Civil Engineering,v.10, n.6, p.362, 1940.

LANE, P. N .J. et al. Water balance of tropical eucalypt plantations in south-eastern China. Agricultural and Forest Meteorology, v.124, n.3, p.253-267, 2004.

LLORENS, P.; DOMINGO, F. Rainfall partitioning by vegetation under mediterranean conditions. A review of studies in Europe. Journal of Hydrology, v.335, n.1, p.37-54, 2007.

MACFARLANE, A. C. et al. Transpiration and hydraulic traits of old and regrowth eucalypt forest in southwestern Australia. Forest Ecology and Management, v.260, n.1, p.96-105, 2010.

MONTEITH, J. L. Evaporation and environment. Symposium of the Society for Experimental Biology,v.19,p.205-234, 1965.

NOSETTO, M. D. et al. Land use change and water losses: the case of grassland afforestation across a soil textural gradient in Central Argentina. Global Change Biology, v.11, n.7,p.1101-1117, 2005.

NOSETTO, M. D. et al. The hydrologic consequences of land cover change in central Argentina. Agriculture, Ecosystems \& Environment, v.11, n. 1, p.1101-1117, 2011.

Revista Árvore, Viçosa-MG, v.37, n.3, p.547-556, 2013 
NOTTER, B. et al. Impacts of environmental change on water resources in the Mt. Kenya region. Journal of Hydrology, v.343, n.2, p.266-278, 2007.

RUTTER, A. J. et al. A predictivemodel of rainfall interception in forests, II. Generalization ofthe model and comparison with observations in some coniferousand hardwood stands.

Journal Applied Ecology, v.12, n.1, p.367-380, 1975.

SILVA, M. A. et al. Sistemas de manejo em plantios florestais de eucalipto e perdas de solo e água na região do vale do rio Doce, $\mathrm{MG}$.

Ciência Florestal, v.21, n.4, p.765-776, 2011.

SOARES, J. V.; ALMEIDA, A.C. Modeling the water balance and soil water fluxes in a fast growing Eucalyptus plantation in Brazil. Journal of Hydrology, v.253, n.1, p.130-147, 2001.
STEIDLE NETO, A. J. et al. Simulation of Rainfall Interception of Canopy and Litter in Eucalyptus Plantation in Tropical Climate. Forest Science, v.58, n.1, p.54-60, 2012. http://dx.doi.org/10.5849/ forsci.09-120

THANAPAKPAWIN, P. et al. Effects of land-use change on the hydrologic regime of the Mae Chaem river basin, NW Thailand. Journal of Hydrology, v.334, n.1, p.215-230, 2007.

von STACKELBERG, N. O. et al. Simulation of the hydrologic effects of aforestation in the Tacuarembó River Basin, Uruguay.

Transactions of the ASABE, v.50, n.3, p.455-468, 2007.

ZHOU, G. H. et al. Hydrological impacts of reafforestation with eucalypts and indigenous species: a case study in southern China. Forest Ecology and Management, v.167, n.1, p.209-222, 2002.

Revista Árvore, Viçosa-MG, v.37, n.3, p.547-556, 2013 